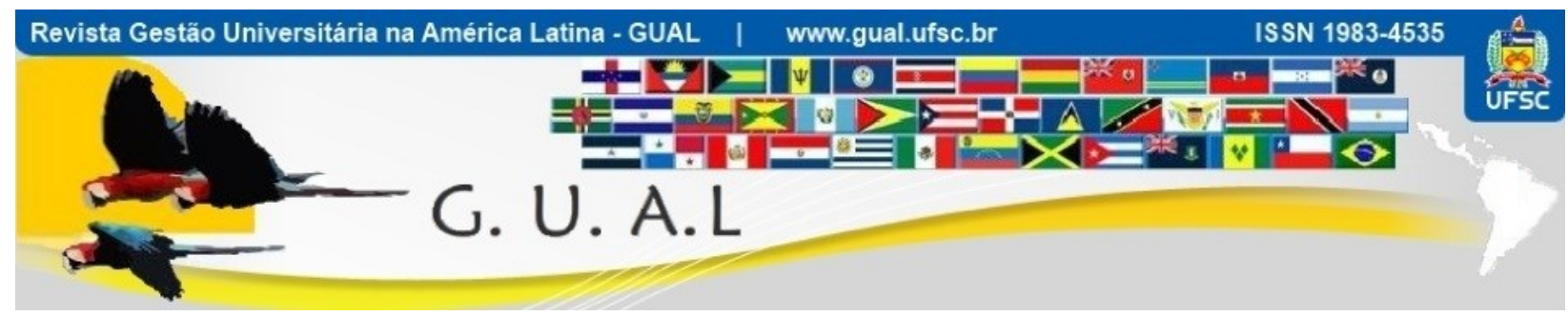

DOI: http://dx.doi.org/10.5007/1983-4535.2015v8n1p282

\title{
CRESCIMENTO DA FIRMA CONTEMPORÂNEA: ESTUDO DE CASO DE UMA INSTITUIÇÃO DE ENSINO SUPERIOR
}

\section{GROWTH OF CONTEMPORARY FIRM: CASE STUDY OF AN INSTITUTION OF HIGHER EDUCATION}

Samuel Martim de Conto, Doutorando

Centro Universitário UNIVATES

samuelc@,univates.br

Carlos Candido da Silva Cyrne, Doutorando Centro Universitário UNIVATES cyrne@univates.br

Júlia Elisabete Barden, Doutora Centro Universitário UNIVATES jbarden@univates.br

Recebido em 24/fevereiro/2014

Aprovado em 05/dezembro/2014

Sistema de Avaliação: Double Blind Review

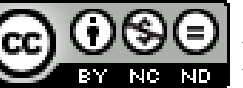

Esta obra está sob uma Licença Creative Commons Atribuição-Uso. 


\title{
RESUMO
}

A concorrência entre as firmas é observada em todos os mercados, sejam elas produtoras de bens ou prestadoras de serviços. Sob o ponto de vista dos vários aspectos concorrenciais e de mercado, uma Instituição de Ensino Superior também se configura como sendo uma firma Penroseana. Diante disso, o estudo propõe-se a analisar o crescimento de uma Instituição de Ensino Superior do Rio Grande do Sul à luz da Teoria da Firma. Para o desenvolvimento desse estudo, o método utilizado foi a abordagem qualitativa e exploratória, utilizando procedimentos técnicos do tipo fontes secundárias, levantamentos bibliográficos sobre o assunto e documentos internos da organização estudada. Como resultado desse estudo são apresentadas considerações sobre o crescimento da organização e identificados correlatos entre a evolução da Instituição e os elementos da Teoria da Firma.

Palavras-chave: Teoria da Firma. UNIVATES. Instituição de Ensino Superior.

\begin{abstract}
The competition among firms is observed in all markets being them producers of goods or services providers. Under the point of view of many competition aspects and market, a Higher Education Institution also configures itself as being a Penrosian firm. Because of that, this study proposes to analyze the growing of a Higher Education Institution of Rio Grande do Sul under the Theory of the Firm. The method used to develop this study was the qualitative and exploratory approach using technical procedures as secondary sources, bibliographic surveys about the issue and internal documents from the examined organization. As the result of this study considerations are presented showing the growing of the organization and identified correlatives between the evolution of the Institution and the elements of the Theory of the Firm.
\end{abstract}

Keywords: Theory of the Firm. UNIVATES. Higher Education Institution. 


\section{INTRODUÇÃO}

$\mathrm{O}$ acirramento da concorrência exige que as organizações se posicionem de maneira mais ativa na sua atuação de mercado, ofertando algum diferencial para se destacar frente às demais. Ainda que essa ideia tenha estado presente na maior parte dos mercados, na última década especialmente, as Instituições de Ensino Superior (IES) também passaram a enfrentar a concorrência de outros agentes. A entrada de grupos econômicos estrangeiros, além de grupos nacionais em expansão, bem como, a expansão do Ensino a Distância, a melhoria na renda e a estabilidade econômica do país, resultou em avanços no número de brasileiros matriculados no Ensino Superior, influenciando e transformando o setor educacional do país.

O movimento de aquisições de IES por grupos econômicos contribuiu para o aumento da competição das organizações atuantes, sob o risco de serem ultrapassadas ou adquiridas por estas. Além disso, a expansão do Ensino a Distância também possibilitou que o tamanho do mercado tivesse apresentado expressivo aumento nos últimos anos.

Como forma de investigação desta situação, são utilizados conhecimentos que estruturam a Teoria da Firma com o objetivo de analisar a natureza, o desenvolvimento e os limites de uma organização, seja ela de qualquer segmento econômico, como, por exemplo, do Ensino Superior.

Esse estudo justifica-se por algumas razões: a primeira, pelo fato de que o setor brasileiro têm se tornado no maior mercado mundial de ensino superior privado, com um faturamento anual de aproximadamente R\$ 30 bilhões (JUSBRASIL, 2012); a segunda, pela importância que a qualificação e especialização da força de trabalho representa para o desenvolvimento econômico e tecnológico de um país; e a terceira, por se tratar de um estudo ainda incipiente com foco em Instituições de Ensino e poder contribuir para o entendimento da dinâmica destas organizações e do setor que pertencem ao setor.

Com base nisso, o objetivo deste artigo é analisar o crescimento de uma Instituição de Ensino Superior do Rio Grande do Sul à luz da Teoria da Firma. Para isso, o artigo se propõe a apresentar referenciais a respeito da Teoria da Firma, a fim de subsidiar à análise do setor educacional, a análise do caso, a metodologia utilizada, e por último, são apresentadas as considerações finais. 


\section{ASPECTOS DA TEORIA DA FIRMA}

\subsection{A NATUREZA E OS LIMITES DE CRESCIMENTO DA FIRMA}

A microeconomia, que em conjunto com a macroeconomia fundamenta a teoria econômica, teve inicialmente a contribuição dos economistas clássicos de que o valor era gerado exclusivamente pelo trabalho. Posteriormente, os neoclássicos rediscutiram estes princípios até então, e inferiram que o valor é gerado pelas relações de oferta e demanda no mercado. Nesse sentido, questionam-se os pressupostos dos clássicos de que toda demanda geraria sua oferta. Essa premissa deveria ser modificada, haja vista que diversas forças são responsáveis pelas relações de oferta e demanda. Neste contexto, a teoria da firma surge com um arcabouço teórico que fundamentou os mecanismos de concorrência dos mercados, em especial das firmas.

Assim, ao contrário daquilo que os clássicos defendiam - o equilíbrio do mercado - o foco deveria ser pelo "desequilíbrio", tendo nas firmas a busca pela evolução tecnológica para que ocorresse num sentido mais amplo o desenvolvimento econômico. Por meio da visão institucional surge a firma, que para Schumpeter (1942) poderia inclusive assumir a estrutura de monopólio, onde o poder de determinado mercado não ocasionaria a estabilização da economia, uma vez que o monopólio é passageiro - principalmente com o desenvolvimento tecnológico. Assim, o que desencadeia a inovação nas firmas é o desequilíbrio, inclusive propiciado pelas grandes monopolistas.

Observa-se que haviam novas ideias defendidas pelos neoclássicos e por Schumpeter que iam de encontro às defendidas pelos economistas clássicos. As firmas precisavam ser próativas (inserir novidades no mercado) para competirem e crescerem, ao contrário daquilo que os clássicos defendiam de que as firmas deveriam buscar o equilíbrio do mercado.

Diante disso, Penrose (1959) elabora um conjunto de conhecimentos objetivando analisar e investigar o crescimento das firmas. A firma é considerada como um conjunto de recursos produtivos e o que determina seu crescimento é o gerenciamento desses recursos conforme suas características internas. A lógica não é a busca incessante pelo lucro, e sim o crescimento da firma. Por sua vez, a racionalidade das pessoas que gerenciam estas organizações não é absoluta, porque as informações não são plenas, isto é, não estão completamente disponíveis para a tomada de decisão. Então, levando em consideração a racionalidade, o que determina o crescimento da firma é o gerenciamento da unidade de planejamento administrativo autônomo, com atividades inter-relacionadas e coordenadas por 
políticas formuladas com vista à efetividade na firma como um todo, orientadas hierarquicamente para a sua administração central.

Jensen e Meckling (2008, p. 90) consideram a firma como a conexão de uma "série de relações contratuais entre indivíduos", sendo assim, é um processo complexo no qual os objetivos conflitantes de indivíduos atingem um equilíbrio por meio das relações contratuais. Para que a funcionalidade ocorra sem obstáculos nas atividades das firmas é necessário políticas como direcionadores do pessoal administrativo. As mudanças (desequilíbrio) suscitam problemas que precisam ser ajustados por meio de planejamento e adoção de políticas de amplo alcance (PENROSE, 1959).

Em relação ao tamanho da firma, na visão clássica das grandes organizações a coordenação era vista como um fator fixo, com rendimentos decrescentes. Já na visão neoclássica, há capacidade da firma de alterar sua estrutura de modo que as decisões pudessem ser tomadas por um grande número de funcionários, sem esquecer o essencial para o seu crescimento (PENROSE, 1959).

Com uma preocupação mais operacional, Coase (1937) menciona que a firma irá internalizar o número de transações que sua estrutura de coordenação conseguirá suportar de maneira mais eficaz do que o mercado. Nessa visão, quanto mais operações as firmas passarem a coordenar, maior será o seu tamanho. Diante disso, para Coase (1937) o limite de crescimento da firma depende da capacidade do empreendedor em lidar de maneira mais eficaz com o maior número de transações. Em outras palavras, uma firma poderá crescer tanto quanto for mais avançada a sua técnica gerencial. Acrescentando ao aspecto, Penrose (1959) menciona que a racionalidade limitada das pessoas é um fator limitador do crescimento das firmas. Sendo assim, é a coordenação que define os limites da firma. É a aptidão em manter uma coordenação administrativa de uma firma produtiva que estabelece seu limite de crescimento.

Da mesma forma, Gonçalves (1991, p. 499) menciona que "mercados e firmas são vistos como formas alternativas de organização da produção e, da mesma forma que existem custos associados à realização de um contrato no mercado, existem custos associados à internalização das atividades na firma". O autor ainda complementa que os custos de transação são determinados pela interação de dois conjuntos de fatores, humanos e ambientais. O primeiro conjunto de fatores refere-se à racionalidade limitada e ao 
oportunismo dos agentes econômicos e o segundo conjunto refere-se aos interesses oportunistas conforme o ambiente se torna mais propício aos agentes.

$\mathrm{O}$ crescimento de uma firma produtiva tem significado econômico para a concentração e controle financeiro, possibilitando usar tal controle na ampliação de recursos produtivos do grupo controlador, levando em alguns casos às estruturas de monopólio ou oligopólio.

Ainda de acordo com Penrose (1959), os recursos materiais de uma firma são considerados tangíveis, como instalações, equipamentos, matérias-primas, bens semiprocessados, refugos, subprodutos, estoques não vendidos e produtos acabados. Já os recursos humanos são apresentados pela força de trabalho qualificada ou não, e pessoal de caráter burocrático, administrativo, financeiro, jurídico, técnico e gerencial.

Entender a motivação da existência das firmas é importante, mas entender a motivação para o lucro também é. Normalmente as grandes firmas são geridas por administradores que também se sentem motivados para ganhar com essa situação. Já para os pequenos empresários o lucro é pouco utilizado em benefício próprio de reinvestimento para a continuidade do negócio (PENROSE, 1959).

A estrutura das pequenas e grandes firmas é diferente, considerando suas especificidades e as estruturas administrativas passam constantemente por mudanças, com vistas à melhoria eficaz da atividade produtiva.

Dentro desse contexto, a firma pode ser entendida como aquela capaz de coordenar de forma mais eficaz o maior número de operações, sejam elas produtivas ou não, objetivando a maximização dos recursos disponíveis. O tamanho que uma firma terá dependerá da sua eficácia em gerenciar dos mais diversos tipos de recursos (ANGONEZI e CONTO, 2006).

Observa-se desde as contribuições de Schumpeter, que a firma é movida por desafios e oportunidades com vistas ao seu crescimento. Entretanto, para Coase e Penrose, há um limite de crescimento da firma, no momento em que a racionalidade limitada das pessoas não for mais eficiente para gerenciar um número cada vez maior de transações. Ou seja, o tamanho que uma firma terá, dependerá da eficiência com que os fatores da organização são gerenciados.

\subsection{CONCORRÊNCIA, INOVAÇÃO E CRESCIMENTO DA FIRMA CONTEMPORÂNEA}

A preocupação de Penrose (1959) em relação ao crescimento da firma, que deveria organizar de maneira mais eficaz os recursos produtivos com vistas ao crescimento da 
atividade, é justificada pelo fato de que as organizações (não somente as industriais) necessitam estar preparadas e qualificadas para atender aos interesses do mercado. $\mathrm{O}$ crescimento da concorrência entre firmas é mais um dos obstáculos que as mesmas enfrentam, caracterizando-se como importante elemento a ser enfrentado para a necessidade de sobrevivência da organização.

No início do Século XX, o crescimento das organizações estava correlacionado à implementação de inovações, visando à eficiência produtiva e operacional. Algumas mudanças foram percebíveis naquele momento, como a produção em linha, a administração científica do trabalho e a linha de montagem móvel. Entretanto, alguns limites ao crescimento da atividade também foram observados, como o questionamento à continuidade da expansão da demanda; o fracionamento das tarefas e a intensificação do trabalho; os estoques ineficientes; a ampliação do capital imobilizado, da burocracia administrativa e do espaço fabril; a ausência de entrosamento com fornecedores e os conflitos trabalhistas entre níveis fabris (COSTA, 2000). Além disso, várias inovações foram introduzidas a fim de aumentar a produção e tornar mais eficiente o processo produtivo. Nas firmas industriais tradicionais, como a automobilística, o menor desperdício de mão de obra e materiais, bem como novas maneiras de relacionamento com outras firmas, possibilitou aumento competitivo das operações e possibilitou vantagens estratégicas consideráveis. Por outro lado, este comportamento também foi percebido em firmas pertencentes aos mais diversos setores da economia. Então, um comportamento iniciado no setor industrial foi apropriado por outras firmas, objetivando o aumento e ganho de competitividade no setor de atuação.

Estes elementos e conceitos utilizados foram questionados, sobretudo tendo em vista os pressupostos neoclássicos sobre concorrência e deseconomias de escala. As indagações sobre o surgimento das firmas e seu crescimento, dependeram além das observações empíricas, da acumulação de conhecimentos que deram origem a novos conceitos e tecnologias (Tigre, 2005).

Os três paradigmas tecnoeconômicos elencados por Tigre (2005), representam a evolução da teoria da firma e a estrutura industrial presente em cada paradigma. $\mathrm{O}$ primeiro momento, compreendido entre final do Século XIX e início do Século XX, foi caracterizado pela Revolução Industrial britânica, com fundamentos da teoria neoclássica do equilíbrio dos mercados, concorrência e racionalidade perfeita dos agentes econômicos. O predomínio no período era de pequenas empresas, com especialização vertical e dependência das economias 
externas. O Estado não tinha interferência na regulação do mercado, permitindo a livre movimentação do sistema econômico (Laissez-faire). O segundo momento, período inicial do Século XX, a atividade produtiva se deu por meio de novas práticas introduzidas pelo movimento fordista, caracterizado por estruturas de mercado, economias de escala e escopo, racionalidade limitada dos agentes - ocasionando o surgimento de custos de transação, e o momento em que se deu o crescimento das firmas. A estrutura das indústrias era de firmas multinacionais, proporcionando o surgimento de oligopólios. Nesse sentido, o Estado passou a ter um papel mais intervencionista, a fim de evitar excessos de poder econômico das firmas atuantes. O terceiro momento, configurado pelo paradigma da informação, estruturado nas teorias econômicas evolucionistas e neoinstitucionalistas, representa o período de constantes mudanças tecnológicas, a presença das instituições como participantes da trajetória tecnológica e a cooperação entre firmas, buscando aumento da competitividade por meio de novas organizações. Nesse sentido, surgem configurações organizacionais como as redes de firmas, procurando fazer frente aos oligopólios com escala global. O Estado torna possível a atuação e crescimento dos negócios, por meio da desregulamentação, permitindo a ampliação da produção e da economia globalizada.

Ainda, em relação às novas configurações organizacionais entre firmas, Britto (2013, p. 345) menciona as seguintes modelos:

1. Alianças estratégicas entre empresas e outras formas de cooperação produtiva e tecnológica.

2. Programas de cooperação específicos, envolvendo agentes com competências em áreas distintas, que interagem entre si para viabilizar determinada inovação.

3. Processos de subcontratação e terceirização realizados por empresas especializadas em determinadas atividades, que dariam origem a redes estruturadas verticalmente no interior de cadeias produtivas.

4. Sistemas flexíveis de produção baseados em relações estáveis e cooperativas entre empresas atuantes em determinado ramo de atividades.

5. Distritos industriais baseados na aglomeração espacial de empresas e outras instituições que interagem entre si no âmbito de determinada região.

6. Sistemas nacionais e regionais de inovação baseados na especialização e interação de diversos tipos de agentes envolvidos com a realização de atividades inovativas (empresas, universidades, outras instituições etc.). 
Assim, em muitos casos, isoladamente a firma contemporânea não possui mecanismos que resultem em ampliação da sua atividade econômica, necessitando para isso, a transformação da sua estrutura organizacional numa nova configuração, que permita por meio de parcerias a sobrevivência no mercado de atuação.

\section{METODOLOGIA}

Não há um método padrão e mais apropriado para qualquer tipo de estudo, "mas espera-se que este seja coerente em relação aos objetivos do projeto e outras limitações práticas de tempo, custo e disponibilidade dos dados" (ROESCH, 2005, p. 126).

Quanto aos objetivos, o estudo caracteriza-se como sendo exploratório, pois busca uma maior compreensão do fenômeno a ser investigado, podendo ser flexível, não estruturado e qualitativo (AAKER et al., 2004). Além disso, é qualitativo, uma vez que visa aprofundar o fenômeno que está sendo analisado (MALHOTRA, 2006).

Quanto aos procedimentos técnicos, o estudo utiliza fontes secundárias, documentos, levantamentos bibliográficos e estudo de caso. As fontes secundárias utilizadas foram buscadas em livros, artigos científicos e documentos internos da organização (MATTAR, 1996). A metodologia do estudo de caso é utilizada quando "faz-se uma questão do tipo 'como' ou 'por que' sobre um conjunto contemporâneo de acontecimentos sobre o qual o pesquisador tem pouco ou nenhum controle" (YIN, 2001, p. 28). Diante disso, o estudo de caso foi realizado no Centro Universitário Univates, Instituição de Ensino Superior comunitária, localizada no Rio Grande do Sul. Os indicadores que foram utilizados para analisar o caso foram a estrutura física, a comunidade acadêmica, os cursos ofertados e algumas atividades desenvolvidas (Tabela 1). Com estes indicadores a análise também ocorreu relacionada com os principais autores que tratam do tema teoria da firma (Quadro 1).

\section{ANÁLISE DO AMBIENTE E DO CASO}

\subsection{ALGUMAS CONSIDERAÇÕES A RESPEITO DO AMBIENTE}

O setor Educacional brasileiro de Ensino Superior é constituído por 2.365 instituições públicas e privadas, conforme o Censo da Educação Superior de 2011 (INEP, 2013). Embora o governo federal tenha adotado várias políticas com o objetivo de expandir as instituições públicas federais, as instituições privadas representam $88 \%$ do total de Instituições de Ensino Superior (IES). Destaca-se ainda na caracterização, que as instituições públicas podem ser 
municipal, estadual ou federal e as instituições privadas podem ser confessionais, privadas com fins lucrativos e privadas sem fins lucrativos, como se caracterizam as comunitárias que estão presentes principalmente nos estados do RS e SC (CM Consultoria, 2011; ABMES, 2011).

Além de representar a maior parcela no total de IES brasileiras, as Instituições particulares também representam aproximadamente $73,7 \%$ do volume total de matrículas do Ensino Superior brasileiro, tendo papel significativo e importante destas firmas no processo de desenvolvimento intelectual, tecnológico, econômico e social.

Analisando-se o mercado de atuação das instituições comunitárias, observa-se em muitos casos o aumento da concorrência provocada principalmente por instituições com baixo investimento em estrutura e manutenção, algumas focadas na economia de escala e deixando de lado a qualidade do ensino, e também exclusivamente mercantilistas. Nesse sentido, as instituições comunitárias estão organizadas em associações, como as gaúchas (Consórcio das Universidades Comunitárias Gaúchas - COMUNG) e as catarinenses (Associação Catarinense das Fundações Educacionais - ACAFE), possibilitando a troca de experiências, o fortalecimento individual das instituições e o aumento da representatividade destas firmas enquanto pertencentes a um setor econômico. Cabe salientar ainda que, ao contrário da maior parte das IES privadas, as comunitárias reinvestem integralmente na atividade o resultado financeiro obtido no período.

Sancionada recentemente pela Presidente da República, Dilma Rousseff, o Projeto de Lei da Câmara (PLC) 1/2013, regulamenta o funcionamento das Instituições Comunitárias de Educação Superior (ICEs). Conforme a Lei, são consideradas universidades comunitárias as instituições que se constituem na forma de associação ou fundação de direito privado, tenham patrimônio pertencente à sociedade civil ou ao poder público, não distribuam sua renda, apliquem integralmente os recursos nas suas atividades e desenvolvam permanentemente ações comunitárias (COMUNG, 2014).

Assim, observa-se uma característica particular destas IES. Enquanto que grandes grupos econômicos de origem nacional e internacional atuam no setor, possibilitando a expansão vertical e horizontal das suas atividades, as IES comunitárias, pelo fato de terem surgido e de estarem fortemente ligadas à comunidade onde atuam, tornam-se menos favoráveis à expansão horizontal. Neste caso, constata-se na UNIVATES a expansão vertical 
das atividades de ensino, de pesquisa e de extensão, resulta no favorecimento do stakeholders, com a qualificação e o desenvolvimento socioeconômico.

\subsection{APRESENTAÇÃO E ANÁLISE DO CASO}

O Centro Universitário Univates está localizado na região do Vale do Taquari , possui o campus central no município de Lajeado e um campus no município de Encantado. Há mais de 40 anos a região conta com Ensino Superior, sendo que na última década, influenciado por fatores como o aumento da demanda, a autonomia universitária, a melhora das condições econômicas e sociais das famílias, entre outros, propiciaram que a UNIVATES expandisse suas atividades de maneira vertical.

A Instituição historicamente oferta aos alunos do Vale do Taquari ${ }^{1}$, bem como aos de fora da região, a oportunidade de realizar sua formação acadêmica sem a necessidade de deslocamento aos grandes centros urbanos. Além disso, sendo uma instituição de direito privado sem fins lucrativos é preciso que o Centro Universitário Univates faça uma gestão responsável dos recursos oriundos das mensalidades de seus alunos. Outra preocupação dos gestores da UNIVATES refere-se ao crescente contingente de alunos com vistas ao ingresso no Ensino Superior, não possuindo grande percentual deles condições necessárias, as mais diversas, de acessar esse serviço. Isso se deve também, em relação aos aspectos financeiros, que as IESs têm de disputar os poucos recursos que esses candidatos possuem com uma série de outras demandas pessoais (aquisição de bens móveis e imóveis), e não somente com outras instituições de ensino, localizadas em sua região ou não. Para fazer frente a esses desafios, é preciso gerir as IESs de uma maneira cada vez mais profissional (CYRNE, 2012).

Observando os principais indicadores da UNIVATES no período comparativo de 2002 e 2012 (Tabela 1), constata-se que o crescimento no número de alunos em todos os níveis de ensino foi acompanhado pelo aumento da estrutura (espaço físico, bibliografia, laboratórios, museus e salas especiais). Além disso, destaca-se o aumento significativo no número de concluintes que anualmente impactam e auxiliam no processo de desenvolvimento regional.

Embora não conste na Tabela 1, haja vista ser consequência do crescimento dos indicadores apresentados, a receita bruta da Instituição apresentou expressivo crescimento no período analisado. Cabe destacar que, o resultado líquido é reinvestido nas atividades da Instituição e na infraestrutura operacional, com acréscimo na estrutura física (prédios e laboratórios), bem como em móveis e equipamentos e principalmente na qualificação do 
corpo docente, com o incremento do número de professores com mestrado e doutorado, por meio de bolsas e financiamentos subsidiados.

Tabela 1 Comparativo dos principais indicadores da UNIVATES - 2002 e 2012.

\begin{tabular}{|c|c|c|c|}
\hline \multirow{2}{*}{ Indicador } & \multicolumn{2}{|c|}{ Ano } & \multirow{2}{*}{ Variação (\%) } \\
\hline & 2002 & 2012 & \\
\hline Alunos Ensino Superior & 5.041 & 8.765 & 73,87 \\
\hline Concluintes do Ensino Superior & 191 & 777 & 306,81 \\
\hline Vagas anuais dos cursos de Graduação & 2.480 & 2.845 & 14,72 \\
\hline Alunos de Pós-Graduação & 320 & 533 & 66,56 \\
\hline Alunos dos Técnicos & 481 & 1.225 & 154,68 \\
\hline Participantes eventos de Extensão & 33.672 & 111.498 & 231,13 \\
\hline Visitas recebidas no Espaço Arte & 7.995 & 20.493 & 156,32 \\
\hline Professores atuantes no Ensino Superior & 197 & 343 & 74,11 \\
\hline Funcionários técnico-administrativos & 311 & 648 & 108,36 \\
\hline Cursos de Ensino Superior & 32 & 46 & 43,75 \\
\hline Cursos de Pós-Graduação & 13 & 22 & 69,23 \\
\hline Cursos Técnicos & 6 & 11 & 83,33 \\
\hline Espaço físico $\left(\mathrm{m}^{2}\right)$ & 31.650 & 60.008 & 89,60 \\
\hline Laboratórios, museus e salas especiais & 48 & 191 & 297,92 \\
\hline Volumes do acervo bibliográfico & 59.997 & 126.917 & 111,54 \\
\hline Projetos de Pesquisa & 47 & 24 & $-48,94$ \\
\hline Convênios e Parcerias & 291 & 1.304 & 348,11 \\
\hline
\end{tabular}

Fonte: Relatórios de Atividades da UNIVATES 2002 e 2012.

O único indicador com variação negativa foi a de número de projetos de pesquisa, embora o percentual da receita bruta aplicado anualmente tenha continuado o mesmo. Algumas considerações ajudam a explicar tal comportamento. Primeiramente, em 2002, a Instituição ampliou sua estrutura de pesquisa, visando à implantação de programas de PósGraduação Stricto Sensu; em segundo lugar, as pesquisas institucionais adotaram a característica multidisciplinar e a formação de grupos de pesquisa, com agregação de pesquisadores de diferentes áreas do conhecimento numa única pesquisa; e em terceiro lugar, o aumento de parcerias e de financiamentos externos possibilitou que os grupos de pesquisa ampliassem a atuação e o escopo de pesquisa.

A interação com a comunidade e demais organizações é percebida pelo indicador dos convênios e parcerias, onde a Instituição atua como prestadora dos mais diversos serviços. Alguns, como análises laboratoriais, são ofertados exclusivamente pela UNIVATES.

Correlacionando este comparativo (Tabela 1) com os elementos essenciais da Teoria da Firma (Quadro 1), observa-se no caso analisado, o crescimento amparado por decisões sustentáveis, levando em consideração os recursos internos disponíveis. Desde o seu início, a 
Instituição procura a evolução tecnológica nas suas atividades, como forma de manter e ampliar seu posicionamento no mercado em que atua. A iniciativa e a pró-atividade sempre foram consideradas nas ações dos colaboradores visando o atendimento das demandas e em consequência disso, promovendo o desenvolvimento regional.

\begin{tabular}{|c|c|}
\hline ELEMENTO & SITUAÇÃO DO CASO ANALISADO \\
\hline $\begin{array}{l}\text { As firmas buscam a evolução tecnológica - } \\
\text { Schumpeter (1942). }\end{array}$ & $\begin{array}{l}\text { A Instituição desde o início das suas atividades - há } \\
\text { mais de } 40 \text { anos - buscou e evolução das tecnologias, } \\
\text { seja por meio da sua própria concepção ou por meio de } \\
\text { aquisições ou parcerias. }\end{array}$ \\
\hline $\begin{array}{l}\text { Possibilidade de assumir a estrutura de } \\
\text { monopólio - Schumpeter (1942). }\end{array}$ & $\begin{array}{l}\text { Tendo em vista o histórico das atividades e a } \\
\text { comprovação da qualidade de ensino, durante mais de } \\
30 \text { anos a Instituição atuou isoladamente na sua região } \\
\text { de abrangência. Nos últimos anos, com a expansão do } \\
\text { Ensino Superior, algumas IES passaram a atuar } \\
\text { presencialmente ou por Ensino a Distância. Entretanto, } \\
\text { a confiança adquirida, a estrutura instalada, a } \\
\text { qualidade dos serviços ofertados, e o envolvimento } \\
\text { com a comunidade regional possibilitaram à } \\
\text { UNIVATES atuar numa estrutura de mercado de } \\
\text { monopólio. }\end{array}$ \\
\hline $\begin{array}{l}\text { As firmas precisavam ser pró-ativas para } \\
\text { competirem e crescerem - Schumpeter } \\
\text { (1942). }\end{array}$ & $\begin{array}{l}\text { Conforme demonstrado por Salvi e Bersch (2007), as } \\
\text { primeiras décadas de atividades da UNIVATES foram } \\
\text { marcados por períodos de intensa participação dos } \\
\text { gestores na superação das inúmeras dificuldades da } \\
\text { época. No entanto, desde o seu início a Instituição agiu } \\
\text { pró-ativamente na ampliação das suas atividades e na } \\
\text { sua consolidação. }\end{array}$ \\
\hline $\begin{array}{l}\text { A firma é considerada como um conjunto de } \\
\text { recursos produtivos e o que determina seu } \\
\text { crescimento é o gerenciamento desses } \\
\text { recursos conforme suas características } \\
\text { internas - Penrose (1959). }\end{array}$ & $\begin{array}{l}\text { Levando em consideração as características de uma } \\
\text { IES Comunitária - Assembleia Geral composta por } \\
\text { membros da comunidade regional ( } 36 \text { municípios), } \\
\text { reinvestimento do resultado financeiro, atendimento às } \\
\text { demandas da região - a firma possui uma gestão } \\
\text { organizada de modo a permitir a ampliação das } \\
\text { atividades, sem comprometer a sua viabilidade. }\end{array}$ \\
\hline $\begin{array}{l}\text { As decisões são tomadas por um grande } \\
\text { número de funcionários da firma, sem } \\
\text { esquecer o essencial para o seu crescimento - } \\
\text { Penrose (1959). }\end{array}$ & $\begin{array}{l}\text { A estrutura interna de gestão da firma em análise } \\
\text { permite tomada de decisão em níveis, desde os } \\
\text { operacionais até os estratégicos. As decisões } \\
\text { estratégicas são ainda validadas em conselhos } \\
\text { consultivos e deliberativos }{ }^{2}\end{array}$ \\
\hline $\begin{array}{l}\text { A firma irá internalizar o número de } \\
\text { transações que sua estrutura de coordenação } \\
\text { conseguir suportar de maneira mais eficaz do } \\
\text { que o mercado. Nessa visão, quanto mais } \\
\text { operações as firmas passarem a coordenar, } \\
\text { maior será seu tamanho - Coase (1937). }\end{array}$ & $\begin{array}{l}\text { O indicador do número de cursos em diferentes níveis } \\
\text { de ensino corrobora com o elemento relativo ao } \\
\text { crescimento da firma. A implantação de um curso } \\
\text { envolve vários recursos da firma: financeiros, } \\
\text { humanos, tecnológicos, conhecimento, estrutura, entre } \\
\text { outros. } \\
\text { Além disso, na UNIVATES foi adotado o } \\
\text { compartilhamento de disciplinas em determinados } \\
\text { cursos, e em determinados semestres, alunos de cursos } \\
\text { diferentes frequentam a mesma sala de aula, cursando }\end{array}$ \\
\hline
\end{tabular}




\begin{tabular}{|l|l|}
\hline \multicolumn{1}{|c|}{ ELEMENTO } & \multicolumn{1}{|c|}{ SITUAÇÃO DO CASO ANALISADO } \\
\hline & $\begin{array}{l}\text { disciplinas comuns constante na matriz curricular dos } \\
\text { cursos. A vantagem na adoção desta prática, por parte } \\
\text { dos alunos, refere-se: à visão multidisciplinar em } \\
\text { relação a uma teoria, acontecimento ou objeto; a } \\
\text { garantia de que a disciplina não será cancelada por } \\
\text { falta de alunos; por parte da Instituição, a } \\
\text { possibilidade de ampliar a atuação na economia de } \\
\text { escala, com racionamento e eficiência da ocupação dos } \\
\text { espaços físicos. }\end{array}$ \\
\hline $\begin{array}{l}\text { A racionalidade limitada das pessoas é um } \\
\text { fator limitador do crescimento das firmas. } \\
\text { Sendo assim, é a coordenação que define os este elemento do crescimento da firma, } \\
\text { limites da firma - Penrose (1959). }\end{array}$ & $\begin{array}{l}\text { educacional requeira implementar determinado curso, } \\
\text { há a necessidade de autorização, pois estão sujeitas aos } \\
\text { agentes regulatórios, orgãos governamentais ou } \\
\text { entidades de classe, como por exemplo para o curso de } \\
\text { Medicina. } \\
\text { Além disso, por se tratar de um centro universitário, a } \\
\text { UNIVATES não possui autonomia para abrir campus } \\
\text { fora da sua sede. Em outros períodos, a Instituição } \\
\text { ofertou cursos em outros municípios, possibilitada } \\
\text { pelas excelentes notas obtidas pelos cursos no antigo } \\
\text { Provão do Ministério da Educação. Entretanto, com o } \\
\text { passar do tempo e com a diminuição da demanda dos } \\
\text { cursos fora de Lajeado, a UNIVATES optou em } \\
\text { investir única e exclusivamente onde está instalado o } \\
\text { campus principal. }\end{array}$ \\
\hline
\end{tabular}

Quadro 1 Elementos essenciais da Teoria da Firma e a situação do caso analisado.

Fonte: Elaborado pelos autores.

A evolução da configuração da firma foi outro fator importante neste período, com novos acordos de cooperação e de integração entre outras IES, principalmente as comunitárias. Fazendo parte do Sistema Regional e Nacional de Inovação, a UNIVATES assumiu um papel mais determinante neste processo, com a implantação do seu Parque Tecnológico. Em parceria com empresas, governos e outras instituições, a iniciativa visa desenvolver e qualificar a área de alimentos e de ambiente, potencialidades da região, como forma de contribuir para o desenvolvimento econômico regional.

\section{CONSIDERAÇÕES FINAIS}

Este estudo objetivou analisar o crescimento de uma Instituição de Ensino Superior do Rio Grande do Sul à luz da Teoria da Firma. Para isso, foram utilizados elementos que fundamentam a Teoria da Firma e permitem a análise do estudo de caso.

Embora a Teoria da Firma seja considerada como mais apropriada para as organizações industriais, observou-se que uma Instituição de Ensino Superior também possui 
características que permitem fazer esta análise. Há uma relação de oferta e demanda por um serviço, e a IES atua num ambiente cada vez mais competitivo. Além disso, possui em seu histórico fatores como iniciativa e pró-atividade com vistas a ampliar seu papel na estrutura de mercado em que atua.

Por fim, cabe mencionar a posição de vanguarda que a Instituição tem obtido, atua e demonstra sua importância à comunidade regional, visa promover o desenvolvimento das áreas do conhecimento e qualificar a estrutura produtiva, tecnológica e econômica do ambiente em que está inserida.

${ }^{1}$ Situada na região central do Rio Grande do Sul, a região do Vale do Taquari é formada por 36 municípios, que totalizam uma área de $4.821,1 \mathrm{Km}^{2}$ (1,71\% do Estado). Em 2010, conforme o Censo Demográfico do IBGE, a Região contava com de 327.822 habitantes (3,07\% da população gaúcha) - a grande maioria de origem alemã, italiana ou açoriana -, a densidade demográfica era de $68,3 \mathrm{hab} / \mathrm{km}^{2}$. Em 2010, o Produto Interno Bruto (PIB) da Região superou R \$ 7,8 bilhões (3,11\% do PIB estadual). No PIB per capita, a média da Região foi de R $\$ 24.239,19$ em 2010. Conforme o Censo do IBGE de 2010, o índice de alfabetização do Vale era de aproximadamente 94\% (IBGE).

${ }^{2}$ Na UNIVATES existem os seguintes conselhos: de cursos; de centros; câmaras (ensino, pesquisa, extensão, marketing, de internacionalização e de TI) e universitário.

\section{REFERÊNCIAS}

AAKER, David A.; KUMAR, V.; DAY, George S. Pesquisa de Marketing. 2a ed. São Paulo: Atlas, 2004.

ABMES. Associação Brasileira de Mantenedoras de Ensino Superior. Números do Ensino Superior Privado no Brasil. Documento disponível em:

http://www.abmes.org.br/abmes/publicacao/detalhe/id/52 Acesso em: 12 de janeiro de 2014.

ANGONEZI, A.; CONTO, S. M. O processo de coordenação como forma de ampliar os limites da firma: estudo de caso da Tramontina Multi Ferramentas. Estudo \& Debate, v. 13, p. 79-91, 2006.

BRITTO, J. Cooperação interindustrial e redes de empresas. In: KUPPER, David; HASENCLECER, Lia (org.). Economia Industrial: fundamentos teóricos e práticas no Brasil. 2 ed. Rio de Janeiro: Campus, 2013.

INEP. Censo da Educação Superior: 2011 - resumo técnico. - Brasília: Instituto Nacional de Estudos e Pesquisas Educacionais Anísio Teixeira, 2013. 114 p.

CYRNE, C. C. S. Avaliando a percepção de importância e desempenho pelos alunos imigrantes e emigrantes em Instituições de Ensino Superior. Revista Funadesp. V.5, n.5 (junho 2012). Brasília: Funadesp, 2012.

CM Consultoria. Estudos e projeções: panorama e propostas. Documento apresentado no IV Congresso Brasileiro de Educação Superior. Disponível em: 
http://www.abmes.org.br/abmes/public/arquivos/documentos/Projeto_10_Milhoes de_Alunos no_Ensino_Superior.pdf Acesso em: 17 de outubro de 2013.

COMUNG. Consórcio das Universidades Comunitárias Gaúchas. Presidente Dilma sanciona lei que reconhece as Universidades Comunitárias. Disponível em: http://www.comung.org.br/noticia?id=220 Acesso em: 15 de janeiro de 2014.

COASE, R. H. The Nature of the Firm. 1937. In: WILLIAMSON, O. E.; WINTER, S.G. The nature of the Firm: origin, evolution and development. New York: Oxford University, 1993.

COSTA, A. B. Inovações e mudanças na organização industrial. Ensaios FEE, Porto Alegre, ano 21, n. 2, p. 7-31, 2000.

GONÇALVES, R. Grupos econômicos: uma análise conceitual e teórica. Revista Brasileira de Economia. Vol.45, no 4, 1991.

IBGE. Instituto Brasileiro de Geografia e Estatística. Dados do Censo Demográfico de 2010. Disponível em: http://www.sidra.ibge.gov.br Acesso em: 15 de novembro de 2013.

JENSEN, M. C.; MECKLING, W. H. Teoria da firma: comportamento dos administradores, custos de agência e estrutura de propriedade. Revista de Administração de Empresas.

Vol.48 no.2, São Paulo Abr./Jun. 2008.

JUSBRASIL. Ensino Superior sobram vagas faltam recursos. Publicado em 29 de julho de 2012. Disponível em: http://avol.jusbrasil.com.br/politica/103397985/ensino-superiorsobram-vagas-faltam-recursos Acesso em 11 de janeiro de 2014.

MALHOTRA, N. K. Pesquisa de Marketing: uma orientação aplicada. Tradução Laura Bocco. 4. ed. Porto Alegre: Bookman, 2006.

MATTAR, F. N. Pesquisa de marketing: metodologia, planejamento. 3. ed. v.1. São Paulo: Atlas, 1996.

PENROSE, E. A teoria do Crescimento da Firma. Campinas, SP: Editora da UNICAMP, 2006. Edição original: 1959.

ROESCH, S. M. A. Projeto de estágio e de pesquisa em administração. 3. ed. São Paulo: Atlas, 2005.

SALVI, E. J.; BERSCH, R. D. Impacto econômico, social e cultural dos Centros Universitários em suas regiões: um estudo de caso. In: O Impacto dos Centros Universitários no Ensino Superior Brasileiro 1997 - 2007. Arthur Roquete de Macedo (Org.). Brasília - DF, novembro de 2007.

SCHUMPETER, J. A. Capitalismo, socialismo e democracia. Rio de Janeiro: Fundo de cultura, 1961. Primeira edição: 1942.

TIGRE, P. Paradigmas tecnológicos e teorias econômicas da firma. Revista Brasileira de Inovação. Volume 4, Número 1, janeiro/junho, 2005.

UNIVATES. Relatório de Atividades de 2002 e 2003. Documento interno. Elaborado por Banco de Dados Regional. 144 p. 2003.

UNIVATES. Relatório de Atividades de 2012. Documento interno. Elaborado por Banco de Dados Regional. 283 p. 2012.

YIN, R. Estudo de Caso. Porto Alegre, Bookman, 2001. 